\title{
Actualizaciones Institucionales
}

\author{
LA ESCUELA DE SALUD \\ PUBLICA: sus orígenes $26^{\circ}$ nota
}

Lic. Mgter. Rubén A. Castro Toschi Méd. Gustavo Martínez Allende

Docentes de la Escuela de Salud Pública - F.C.M. U.N.C.

\begin{abstract}
Al finalizar las actividades del ciclo lectivo1999 la Escuela de Salud Pública de la Facultad de Ciencias Médicas de la Universidad Nacional de Córdoba, eleva la síntesis informativa de las acciones desarrolladas durante este vigésimo segundo año consecutivo de formación de posgrado, con la dirección a cargo del Prof. Dr. Carlos Alberto Lopresti como Director de la Escuela de Salud Pública y al Prof. Ivo Ferrari como Vice Director según RHCD 1755, quienes habían sido designados desde el 24 de setiembre del año 1998. Y luego por RHCD n 0351 se acepta la renuncia de este último y en su reemplazo se designa interinamente a la Sra. Prof. Dra. Gladys Martelloto, siendo Decano el Prof. Dr. Héctor David Ferreyra.

\section{LA PLANTA DOCENTE ESTUVO CONFORMADA POR LOS SIGUIENTES DOCENTES:}

- Prof. Dr. ARANEGA, César Ignacio Prof. Titular

- Prof. Dr. FERRARI, Ivo

Prof. Adjunto (s)

- Dr. MARECA, Oscar Gerardo Prof. Adjunto (s)

- Dr. MICHREF, Jorge

Prof. Adjunto (s)

- Dr. GARCIA, Luis Tomás

Prof. Adjunto (s)

- Ing. Químico, PAVON, Daniel A. Prof. Adjunto (s) *

- Dr. GIMENO BALAGUER, Eugenio Prof. Adjunto (s)
\end{abstract}


- Méd. RAHAL, Abelardo

JTP (sd)

- Méd. Mgter. ACEVEDO, Gabriel

JTP (sd)

- Lic. Mgter. CASTRO TOSCHI, Rubén

JTP (s)

- Odont. CAPPELLINI, María Lourdes

- Méd. Mgter. DIONISIO, Leandro

- Méd. FERRO, Rubén Oscar

- Méd. MARTINEZ ALLENDE, Gustavo

- Méd. Mgter. MIRAVET, Marcela

- Méd. TABORDA, Juan Carlos

- Lic. ZOROASTRO, Gastón

- Méd. ZUCARIA, José

(*) en reemplazo del Prof. Jorge Michref en cargo vacante por fallecimiento

Además de la actividad base de la Escuela como lo es el Diplomado en Salud Pública, continuó el desarrollo de la carrera de Maestría en Gerencia y Administración de Servicios de Salud en la cohorte 98/99.

\section{Actividades Destacadas}

Una nueva Colación de Grados tuvo la Escuela de Salud Pública destacándose en esta XXV Promoción de Diplomados en Salud Pública la presencia del Honorable Consejo Directivo de la Facultad de Ciencias Médicas, y las relevantes palabras del señor Decano el Prof. Dr. Héctor David Ferreyra.

\section{CARRERA DE DIPLOMADO EN SALUD PÚBLICA}

\section{CURSANTES 1999}

- APELLA, Ernesto

- BARALE, Susana

- BERGERO, Dante Fernando

- BISIO, Juan Francisco

- CELLENZA, Alicia Catalina

- DE PASCALE, Alejandro

- FONSECA, María de los Ángeles

- GERBAUDO, Genaro Rafael

- GODOY, Gabriel José

- GOMEZ, Jorge Oscar

- JAIME, María Graciela
Médico

Médico

Médico

Farmacéutico

Médica

Lic. Produc. Bioimagen

Médica

Médico

Médico

Médico

Médica 
- MARENGO, Graciela Edith

- OLSEN, Ernesto Claudio

- PAZ, Irma Yolanda

- PEIRETTI, Gabriela Beatriz

- SPINELLI, Marcos Abel

- STEFANOVICH, Ester Catalina
Médica

Médico

Médico

Médica

Médica

Médico

La Resolución Decanal n 338/99 autorizó la realización durante el ciclo lectivo 1999 de las siguiente actividades académicas:

1.- CURSO DE POSTGRADO SOBRE EDUCACION PARA LA SALUD, a desarrollarse en nueve módulos mensuales (de abril a diciembre) bajo la dirección de la Dra. Amelia López, la conducción docente de la Lic. Julia Linetzky y la coordinación del LIc. Mgter. Rubén Castro Toschi.

2.- CURSO DE POSTGRADO SOBRE GESTION Y AUDITORIA EN ODONTOLOGIA (nivel I), a desarrollarse en nueve módulos (de abril a diciembre ) bajo la dirección de la Odont. DSP María Lourdes Cappellini y la coordinación del Odont. DSP Alejandro Ochoa.

3.- SEPTIMO SEMINARIO TALLER DE POSTGRADO SOBRE DIRECCION EN SALUD (PRIMER NIVEL) a desarrollarse en nueve módulos (de marzo a noviembre) bajo la dirección del Lic. Mgter. Rubén Castro Toschi y la coordinación del Arq. Mgter. Luis Eduardo Carreño.

4.- CURSO DE POSTGRADO SOBRE ADMINISTRACION DE SERVICIOS DE SALUD MENTAL, a desarrollarse en nueve módulos (de abril a diciembre) bajo la dirección del Prof. Dr. José María Willington, la coordinación del Dr. Juan Carlos Taborda y la conducción docente del Dr. Rubén Oscar Ferro.

5.- CURSO DE POSTGRADO SOBRE REESTRUCTURACION DE LOS SERVICIOS DE SALUD MUNICIPALES, a desarrollarse en ocho módulos ( de abril a noviembre), bajo la dirección del Dr. Gustavo Martínez, la coordinación del Méd. Mgter. Leandro Dionisio y la conducción docente del Méd. DSP, Carlos Tolosa.

6.- CURSO DE POSTGRADO SOBRE CALIDAD Y EVALUACION DE LOS SERVICIOS DE SALUD, a desarrollarse en seis módulos (de mayo a octubre( bajo la dirección del Dr. Gabriel Pedetta, la coordinación de la Lic. Susana Slocowski y la conducción docente de la Lic. Mgter. Alicia Casarin.

7.- SEMINARIO TALLER DE POSTGRADO SOBRE DIRECCION EN SALUD (NIVEL II), a desarrollarse en cinco módulos (de mayo a setiembre) bajo la dirección del Arq. Mgter. Luis Eduardo Carreño y la coordinación del Méd. Mgter. Gabriel Acevedo.

8.- CURSO DE POSTGRADO SOBRE ADMINISTRACION HOSPITALARIA, a desarrollarse en nueve módulos (de abril a diciembre) bajo la dirección del Prof. Dr. Oscar Gerardo Mareca y la coordinación de la lic.Mgter. Bonifacia Colman.

9.- CURSO DE POSTGRADO SOBRE METODOLOGIA DE LA INVESTIGACION Y BIOESTADISTICAS APLICADAS A SALUD, a desarrollarse en cinco módulos ( de mayo a setiembre) bajo la dirección del Prof. Dr. Ivo Ferrari y la coordinación del Lic. Gastón Zoroastro.

10.- CURSO DE POSTGRADO SOBRE AUDITORIA MEDICA (nivel III) a desarrollarse en siete módulos (de abril a octubre) bajo la dirección del Prof. Dr.Oscar 
Gerardo Mareca y la Dra. Cristina Osan y la coordinación docente de la Dra. Marcela Grifone y el Lic. Mgter. Rubén CastroToschi.

11.- CURSO DE POSTGRADO SOBRE AUDITORIA ODONTOLOGICA (nivel II), a desarrollarse en nueve módulos (de abril a diciembre) bajo la dirección de la Od. DSP María Lourdes Cappelini y la coordinación del Od. DSP Alejandro Ochoa.

12. CURSO DE POSTGRDO SOBRE EPIDEMIOLOGIA, a desarrollarse en siete módulos (de mayo a noviembre) bajo la dirección del Dr. Juan Carlos Estario y la coordinación del Médico DSP Jaime Mazal.

13.- CURSO DE POSTGRADO SOBRE INTRODUCCION AL ESTUDIO DE LAS ACCIONES SANITARIAS, a desarrollarse en cuatro módulos ( de junio a setiembre), bajo la dirección del Dr. Mgter. Gabriel Pedetta y la coordinación del Bioq. DSP, Carlos Giorgini.

14.- CURSO DE POSTGRADO SOBRE SEGURIDAD HOSPITALARIA Y BIOSEGURIDAD, a desarrollarse en cinco módulos (de mayo a setiembre) bajo la dirección del Prof. Dr. Ivo Ferrari y la coordinación del Dr. José Zucaría.

15.- CURSO DE POSTGRADO SOBRE LEGISLACION SANITARIA, a desarrollarse en cinco módulos (de julio a noviembre), bajo la dirección de la Dra. María Emilia Luna y la coordinación del Dr. Juan Carlos Taborda.

La Resolución Decanal n 1814 de fecha 18 de octubre de 1999 resolvió autorizar la realización del Curso de actualización en Salud Pública, bajo la dirección de la señora Profesora Dra. Gladys Martellotto desde el 23 de setiembre al 25 de noviembre de 1999. Esta actividad convocó a muchos Diplomados en Salud Pública (DSP) que luego pudieron acceder a la novel Maestría en Salud Pública.

\section{Bibliografía:}

Escuela de Salud Pública F.C.M. Memorias Anuales, Córdoba 1974/1999

Escuela de Salud Pública F.C.M. Sec. Administrativa, archivos, Córdoba 1974/2016

Digesto de Resoluciones Decanales, Fac. de Cs. Médicas, UNC 1974/ 1999

Digesto de Resoluciones H:C.D. Fac, de Ciencias Médicas, UNC, 1974/1999

Archivos de la Facultad de Ciencias Médicas de la UNC.

Archivo Histórico de la Universidad Nacional de Córdoba. 